\title{
Retracted: Chronic Recurrent Multifocal Osteomyelitis with Concomitant Features of Juvenile Idiopathic Arthritis
}

\author{
Case Reports in Rheumatology \\ Received 20 August 2014; Accepted 20 August 2014; Published 28 August 2014 \\ Copyright (C) 2014 Case Reports in Rheumatology. This is an open access article distributed under the Creative Commons \\ Attribution License, which permits unrestricted use, distribution, and reproduction in any medium, provided the original work is \\ properly cited.
}

The paper titled "Chronic recurrent multifocal osteomyelitis with concomitant features of juvenile idiopathic arthritis" [1], published in Case Reports in Rheumatology, has been retracted as it was submitted for publication without receiving the patient's consent to be included in the study.

\section{References}

[1] E. Tsitsami, V. Dermentzoglou, M. Moschovi, and G. P. Chrousos, "Chronic recurrent multifocal osteomyelitis with concomitant features of juvenile idiopathic arthritis," Case Reports in Rheumatology, vol. 2011, Article ID 210795, 6 pages, 2011. 